\title{
EVALUATION OF THE SEISMIC RESPONSE OF BASE ISOLATED FRAME STRUCTURES WITH DIFFERENT HEIGHTS
}

\author{
Waleed Abo El-Wafa Mohamed \\ Civil Engineering Department, Faculty of Engineering, Assiut University, \\ Assiut, Egypt. \\ Mohamed Abdel-Basset Abdo \\ Civil Engineering Department, Faculty of Engineering, Assiut University, \\ Assiut, Egypt.
}

(Received August 5, 2006 Accepted August 26, 2006)

\begin{abstract}
Base isolation technology has emerged in the last decades as an innovative seismic design approach aimed at reducing the damage of structures when subjected to earthquake excitations by separating the building from the surrounding ground motions. This paper presents nonlinear seismic analysis of steel structures with 5, 10 and 20 stories designed to meet the requirements of a newly developed code. The structure is either conventional with fixed base or base isolated with different types of elastomeric bearings. A numerical parametric study is carried out to recommend the effective range of isolation bearing parameters represented by the ratio of fundamental period of the isolated structure related to that of corresponding fixed base one. This range is evaluated relying on the performance of both superstructure and elastomeric isolation bearings. The peak responses of the different studied frames are examined to determine the effectiveness of the utilized system.
\end{abstract}

KEYWORDS: seismic response, steel frames, base isolation, elastomeric bearings and ductility demand.

\section{INTRODUCTION}

The last experienced earthquakes that chock different countries in the world during the last decades reported that a significant number of steel frame structures suffered extensive damage, requiring extensive repair and upgrading work. Although bracing systems were among the most efficient structural systems in steel construction to enhance the lateral stiffness of the unbraced frames and absorbing seismic forces, they also resulted in rather poor behavior under severe ground motions. While the total and catastrophic failures of steel structures and the resulting loss of life have not been too common in the past, recent experiences suggest the need for evaluating the damage potential of such structures and hence developing new effective systems for an earthquake resistance design [1], [2].

The philosophy of conventional earthquake - resistance design is based on that the structural damage should be minimized or avoided in moderate earthquakes while 
the structural safety must be assured in extreme earthquakes. This requires that the structure should obtain sufficient strength to withstand earthquake forces and adequate ductility to absorb earthquake energy [3]. Base isolation is today considered as an innovated aseismic approach for earthquake hazard mitigation. Superior seismic performance can be achieved by means of introducing a set of flexible isolators between a stiff superstructure and its foundation to decouple the structure from potentially damaging earthquake induced ground motions. This decoupling is achieved by increasing the flexibility of the system along with providing adequate damping [4], [5]. There are many kinds of isolation systems, however they can be classified into three main categories, i.e., pure friction (P-F) system; resilient- friction base isolators (R-FBI), elastomeric multilayer bearing systems which include rubber bearings (RB) and lead rubber bearings (LRB) [6], [7]. Among these systems, the elstomeric bearings have gained wide acceptance and were used in several buildings in Japan, Europe and United States [8], [9].

Although the practical application of base isolation has taken place only in the last few decades it has been well reviewed [10], [11]. The performance of actually excited base isolated buildings under real quakes as 1994 Northridge and 1995 Kobe ground motions is identified and proved to be satisfied [12], [13]. The characteristic features and suggested models of the elastomeric bearings are reported in some studies [14], [15]. Pseudodynamic and shaking tables experimental studies are carried out on modeled base isolated structures as illustrated in [16] and [17]. Numerical results examining the seismic or wind response of some base isolated structures, especially reinforced concrete ones are also found in literature [18], [19]. In these studies it was proved in most cases that the concept of seismic isolation is effective in hazard mitigation. However, the comparative seismic response of steel structures with different heights, utilizing elastomeric bearings with different parameters and designed according to the newly developed design codes under different real earthquake excitations has to be investigated.

This study comes to evaluate the nonlinear seismic response of based isolated steel frame structures with different heights versus the conventional fixed base ones. A symmetric $32.0 \times 24.0 \mathrm{~m}$ steel framed structures with 5, 10 and 20 stories are designed according to the 1997 Edition of the Uniform Building Code (UBC) [20]. Planar frame is extracted from each structure and subjected to different accelograms representing real earthquakes with different intensities and site conditions. Two types of elastomeric bearings, (RB) and lead rubber bearings (LRB) are installed between the superstructure and foundations as a base isolators, however, this study could be extended to investigate other isolation systems with same technique. A wide range of isolation parameters represented by period shift is studied. The specific objectives of this investigation is to:

(i) Study the response of fixed base steel structures designed according to the UBC 97 under real earthquake excitations,

(ii) Examine the effect of frame height on the performance of base isolated frames utilizing either laminated rubber (RB) or lead rubber bearings (LRB) and

(iii) Suggest the effective ranges of isolation parameters which highly ensure the safety of the structure taking into consideration the cost of the bearings. 


\section{DESCRIPTION AND DESIGN OF STUDIED STRUCTURE}

For the purpose of carrying out an integrated study to evaluate the response of base isolated frame structures, a typical steed frame structure is considered. The structure is symmetric with three bays by four bays, each bay is $8.0 \mathrm{~m}$ long. The total dimensions of the structure are $32.0 \times 24.0 \mathrm{~m}$ as shown in Fig. 1. Three cases with different heights of the structure are studied which are 5,10 and 20 stories to represent, respectively, low, medium and rather high rise structures. The height of the first story in all structures is $4.0 \mathrm{~m}$ while the height of the successive stories is $3.5 \mathrm{~m}$. Because of the symmetry of the building, only the planner interior frame A. A is chosen to be explicitly modeled in each case, the elevation of the frames of the different cases are shown in Fig. 2. The base isolated frames utilize devices, either laminated rubber (RB) or lead rubber (LRB). A rigid girder is supposed to be placed over the isolators to increase the effectiveness of the isolation devices [19].

To evaluate the response of fixed base frame structures designed according to a new edition of recently developed code, after the experience of damaging quake motions, the studied frames are designed to meet the requirements of the 1997 uniform building code (UBC) for buildings located in zone 4, zone expected to be subjected to high intensity quakes, and founded on stiff soil profile (soil type SD). The design gravity loads of each story of the structure include dead load equal $6.0 \mathrm{kPa}$, live load equal $3.0 \mathrm{kPa}$ and external cladding of $1.7 \mathrm{kPa}$.

Because its regularity and that the maximum height of the structure with 20 stories is $70.50 \mathrm{~m}$, less than the $73.00 \mathrm{~m}$ specified by UBC for dynamic analysis, the equivalent static force procedure is adopted in the design of the 3-D full structure. The dead load $\mathrm{W}$ used to calculate the base shear includes not only the dead load of the structure but also partitions and $25 \%$ of the floor live loads. The structure is designed as ordinary moment resisting frame (OMRF). An axial load - moment interaction as per load and resistance factor design (LRFD) is considered for the columns. The steel frames are designed assuming rigid beam- column connections and fixed supports.

The steel grade is assumed to be St. 37, for the selected planar frames of the three studied cases, broad flange I sections are used for beams and collected in three different groups. Hollow circular sections, which are widely used nowadays, are adopted for the design of each column, the resulted sections are collected in eight groups. The designed steel sections of beams and columns are illustrated in Fig. 2. and given in Tables 1 and 2.
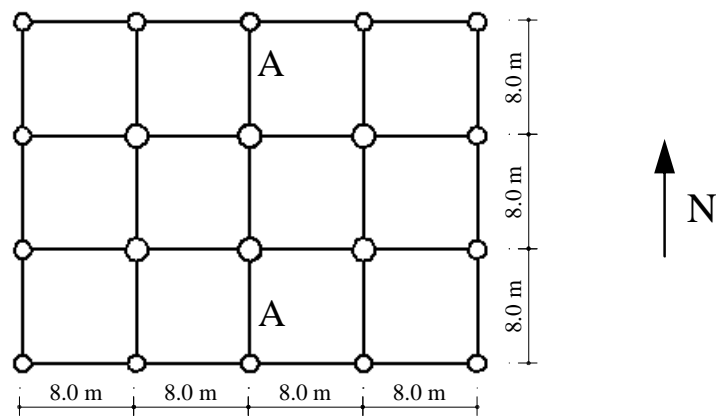

Fig. 1: Plan of the studied structure. 


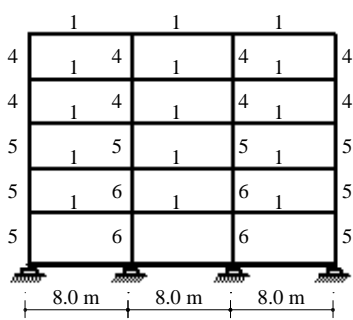

a) 5 stories

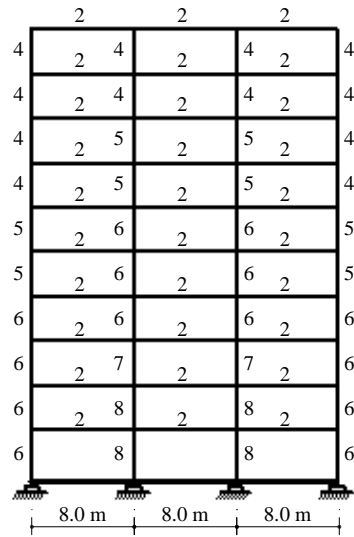

b) 10 stories

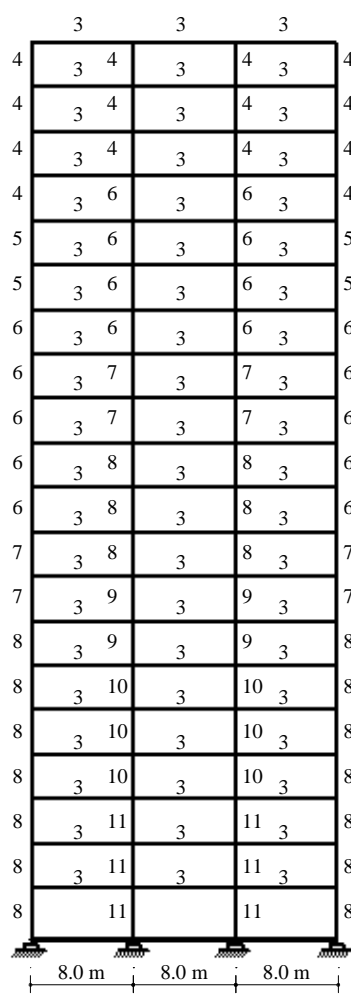

c) 20 stories

Fig. 2: Elevation of frames with different heights.

Table 1: Optimum design of broad flange beam sections.

\begin{tabular}{|c|c|c|c|}
\hline Group No. & 1 & 2 & 3 \\
\hline Sec. & BFIB No. 32 & BFIB No. 40 & BFIB No. 45 \\
\hline
\end{tabular}

Table 2: Optimum design of circular column sections.

\begin{tabular}{|c|c|c|c|c|c|c|c|c|}
\hline Group. No. & 1 & 2 & 3 & 4 & 5 & 6 & 7 & 8 \\
\hline Diameter (m) & 0.40 & 0.50 & 0.60 & 0.70 & 0.80 & 0.90 & 0.95 & 1.05 \\
\hline Thickness (m) & 0.02 & 0.02 & 0.025 & 0.025 & 0.03 & 0.035 & 0.035 & 0.035 \\
\hline
\end{tabular}

\section{SEISMIC BASE ISOLATION: DESCRIPTION AND DESIGN}

The concept of seismic base isolation aiming at the protection of structures from earthquakes has been proposed in various forms at numerous times during the last decades. In this study two leading base isolation devices which are laminated rubber bearings (RB) and lead rubber bearings (LRB) are utilized as seismic base isolation devices. A brief description about the two types are introduced hereafter. 
I) Laminated rubber bearings (RB):

These bearings were fully developed for the applications of bridges, more recently, their use has been extended to the seismic isolation of buildings. Laminated rubber bearings consist of layers of natural rubber sheets being volcanized to steel plates. The steel plates constrain the lateral deformation of the rubber under vertical loading, resulting in a vertical stiffness several times of magnitude greater than the horizontal stiffness. The lateral stiffness depends on the number and thickness of the rubber sheets. Increasing either quantity decreases the stiffness. The dominant feature of the rubber bearing system is the parallel action of linear spring and damping. Schematic diagram representing the linear behavior with viscous damping of rubber bearing system is shown in Fig. 3 (a). The model captures the behavior of bearing is shown in Fig. 3 (b), in which the restoring force developed in the bearing $F_{b}$ is given related to the bearing displacement $x_{b}$ and bearing velocity ${ }_{x} b$ by Eq. (1)

$$
F_{b}=C_{b} \dot{x}_{b}+K_{b} x_{b}
$$

where $C_{b}$ and $K_{b}$ are damping and stiffness of rubber bearing systems, respectively. In this study the damping ratio of rubber bearings is taken equal to 0.10 [3].

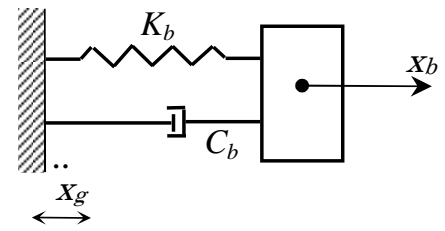

a) Schematic diagram

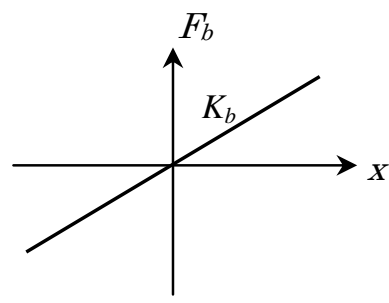

b) Model of RB

Fig. 3: Behavior of laminated rubber bearings (RB).

II) Lead rubber bearings (LRB):

These bearings are similar to the RB but a central lead core is used to provide an additional means of hysteretic energy dissipation and initial rigidity against minor earthquakes and winds. The LRB also provide an additional hystereric damping through the yielding of lead core. Thus, one device is capable of supporting the structure vertically, to provide the horizontal flexibility together with the restoring force, and to provide the required damping. The schematic diagram of the bearing is shown in Fig. 4 (a). To idealize LRB system, the bilinear curve proved to accurately capture the real behavior of such types of bearings [7]. The bilinear model is shown in Fig. 4 (b) in which, $K_{b}$ represents the elastic stiffness which is a property of the material of bearing. The inelastic stiffness $K_{d}$ is proportional to the size of bearing. The yield force $F_{y}$ is proportional to both bearing size and lead radius. As the ratio of $K_{d} / K_{b}$ ranges between 0.025 and 0.35 [14], in this study it is taken dominantly equal to 0.15 [21]. As the ratio between maximum displacement $x_{m}$ and yield displacement $x_{y}$ can take a value between 2 and 20 [14], in this investigation, the yield displacement is kept equal to $0.04 \mathrm{~m}$ to ensure the convenience of structure under wind and minor quake loads. In order to determine the parameters of nonlinear LRB model, first a 
linear model using $K_{\text {eff }}$ along with $C_{e q}$ is used to determine the values of $x_{m}$ and $F_{m}$, hence the values of $K_{b}$ and $K_{d}$ can be obtained. The equivalent damping ratio $\xi_{e}$ is checked in each case and expressed in Eq. 2 [21]:

$$
\xi_{e}=\frac{2 Q_{d}\left(x_{m}-x_{y}\right)}{\pi K_{e f f} x_{m}^{2}}
$$

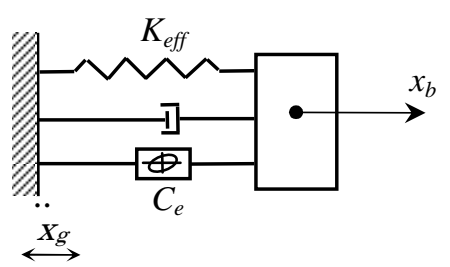

a) Schematic diagram

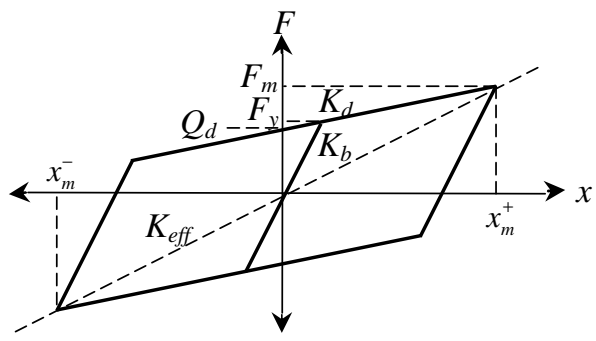

b) Model of LRB

Fig. 4: Behavior of lead rubber bearings (LRB).

To intensively study the behavior of frames isolated in base and recommend the range of effective isolation, a wide range of isolation flexibility is studied. The base isolated frames are designed assuming the same strength of the corresponding fixes base frame but considering different values of isolation flexibilities. To do so, the isolation systems are designed to achieve a shift in the period of the fundamental mode relative to the period of the fundamental mode corresponding to the fixed base one $(F P R)$, hence, $F P R=T_{b} / T_{f}$, in which $T_{b}$ represents the fundameantal period of the base isolated frame and $T_{f}$ is the fundamental period of the fixed base frame. The studied valued of $F P R$ are 1 (represing the fixed base frame), 1.5, 2, 3, 4, 5 and 6 . The fundamental period of vibration of the studied frames and the effective elastic sttiffenes corresponding to each case are illustrated in Table 3.

Table 3: Values of $K_{\text {eff }}$ and $T_{b}$ corresponding to the values of FPR.

\begin{tabular}{|c|c|c|c|c|c|c|c|c|}
\hline \multicolumn{2}{|c|}{$F P R$} & 1 & 1.5 & 2 & 3 & 4 & 5 & 6 \\
\hline \multirow{2}{*}{ 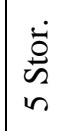 } & $K_{e f f}(k N / m)$ & $\alpha$ & 6000 & 1900 & 500 & 250 & 150 & 100 \\
\hline & $T_{b}(\mathrm{sec})$ & 0.51 & 0.77 & 1.02 & 1.53 & 2.04 & 2.55 & 3.06 \\
\hline \multirow{2}{*}{$\begin{array}{l}\dot{\overrightarrow{0}} \\
\dot{\omega} \\
0\end{array}$} & $K_{\text {eff }}(\mathrm{kN} / \mathrm{m})$ & $\alpha$ & 3600 & 1100 & 380 & 200 & 125 & 85 \\
\hline & $T_{b}(\mathrm{sec})$ & 0.81 & 1.22 & 1.68 & 2.44 & 3.26 & 4.07 & 4.88 \\
\hline \multirow{2}{*}{$\begin{array}{l}\dot{\overline{0}} \\
\dot{n} \\
\stackrel{\sim}{N}\end{array}$} & $K_{\text {eff }}(k N / m)$ & $\alpha$ & 2000 & 730 & 270 & 141 & 87 & 60 \\
\hline & $T_{b}(\mathrm{sec})$ & 1.46 & 2.19 & 2.92 & 4.38 & 5.84 & 7.30 & 8.76 \\
\hline
\end{tabular}




\section{4- SUMMARY OF METHOD OF ANALYSIS}

Because The studied system is non - classically damped due to the differences in damping between the isolation bearings and the superstructure, and also the nonlinearities evolved from the LRB, the classical mode superposition can not be applied. The method of nonlinear time history is applied after carrying out static load and eigenvalue analysis. The general purpose finite element code ADINA [22] is used for the numerical analysis.

Three planner frames with different heights are modeled using elasto-plastic beam elements. The material nonlinearity is modeled through bilinear stress - strain relationship with a second inclination of 0.05 of the initial modulus to take into consideration the hardening law. The yield stress and elastic modulus are equal to 240 $\mathrm{MPa}$ and $200 \mathrm{GPa}$, respectively [23]. RB and LRB are modeled using linear and hysteretic nonlinear truss elements, respectively. The rotational stiffness of bearings is modeled using spring elements.

The time history analysis is conducted for real earthquakes using direct integrations. The equations of motions are solved numerically using Newmark's method of step-by-step, the values of delta and alpha are taken equal to 0.50 and 0.25 , respectively. For the direct integration scheme used in the analysis, the damping matrix must be explicitly evaluated. The choice of Rayleigh damping can effectively capture the damping of the structure. For the steel frames a Rayleigh damping with structural damping ratio $\xi=3 \%[24]$ is used in this study.

\section{5- EARTHQUAKE GROUND MOTIONS}

For the sake of evaluating the nonlinear response of the studied frames when subjected to earthquake excitations, four different real accelograms recorded in three earthquakes are utilized. The applied quakes, in this study, shock different countries, have different levels of intensities ranging between 0.479 and 1.226, also they have different site conditions. The studied earthquakes are: The Loma Prieta, Kobe (with two different accelograms recorded in different places) and San Fernando. Each quake is applied in the north direction of the structure. Table 4 shows some characteristics of the earthquake ground motions. The time histories of the historical earthquakes are shown in Fig. 5. As the response of the structure is not only affected by the intensity of the quake but also by there spectral acceleration, the spectral accelerations of the used records with damping ratio equal 0.03 are illustrated in Fig. 6.

Table 4: Earthquakes data.

\begin{tabular}{|c|c|c|c|c|c|c|}
\hline Earthquake & Date & Station & Comp. & Abbr. & Ms & $\mathrm{A}_{\max }(\mathrm{g})$ \\
\hline San Fernando & Sep. 1971 & Pacoima Dam & 000 & Fer & 6.6 & 1.226 \\
\hline \multirow{2}{*}{ Kobe } & \multirow{2}{*}{ Jan. 1995 } & KJMA & 000 & KJM & 6.9 & 0.821 \\
\cline { 3 - 8 } & & Takatori & 000 & Tak & 6.9 & 0.611 \\
\hline Loma Prieta & Oct. 1989 & Corralitons & 090 & Lom & 6.9 & 0.479 \\
\hline
\end{tabular}



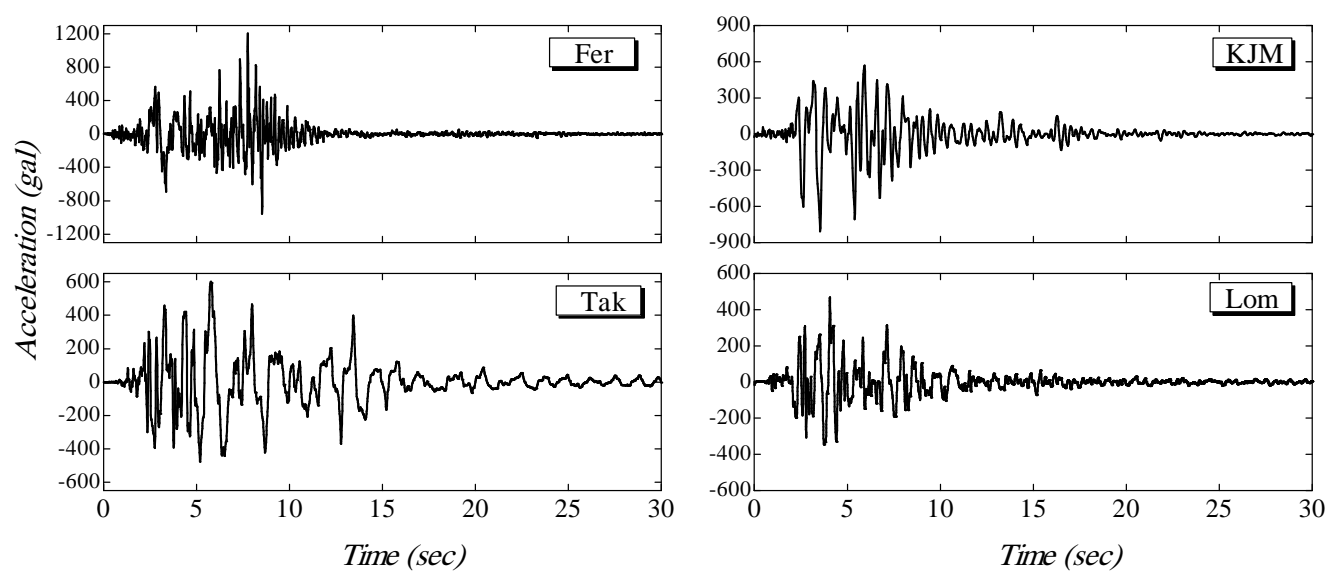

Fig. 5: Time histories of the applied earthquakes.
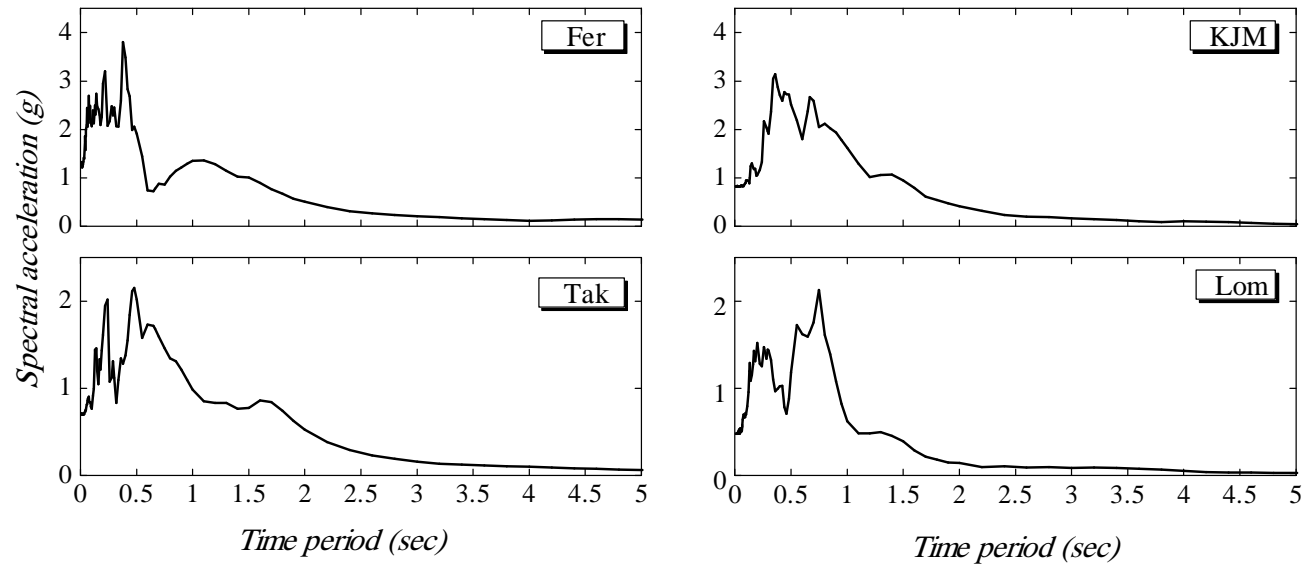

Fig. 6: Response spectra of the applied earthquakes.

\section{6- STRUCTURAL RESPONSE UNDER SEISMIC EXCITATIONS}

The main benefit that can be gained from inserting elastomeric isolation bearings between the superstructure and the foundation is to provide lateral flexibility to the structure. This lateral flexibility results in a shift of the structure period depending on the feature characteristics of bearings. To evaluate the seismic response of the test structure subjected to the different four accelograms, a parametric investigation is carried out relying on the values of the fundamental period ratio $(F P R)$ ranging between 1 (case of fixed base frame) and 6 . The nonlinear response of the selected frames is introduced in the next section in the form of peak values of column bending moment, mean ductility demand, floor accelerations, story drift ratios and bearing displacement.

The columns of all the fixed base OMRF with the three different heights suffer high inelastic bending moments under Fer, KJM and Tak earthquakes. The Lom quake, even it has the lowest intensity, could cause relatively high plasticity in the 
columns of the 10 stories frame with fixed base as the earthquake energy is dominant in the period of 0.75 which is close to the fundamental period of this frame. The peak $M / M_{y}$ ratios for fixed base frames reached up to 1.30 for the 5 stories frame and 1.56 for 10 and 20 story frames, respectively. Utilizing elastomeric bearings can drastically eliminate the inelastic damage concentrated in columns of fixed base frames for FPR beyond 2 in case of LRB and beyond 3 in case of RB as shown in Fig. 7 due to the achieved flexibility and period shift. As the FPR increases, the peak bending moment sharply decreases up to FPR equal 3 or 4 , beyond these values a slight enhancement in the behavior could be observed. The trend of the bending moment behavior is almost close for both types of elastomeric bearings, however, the performance of frames isolated with LRB is better than the response of those isolated with RB, especially for FPR less than 4. This behavior is related to the extra damping and energy dissipation provided by the lead core. It is clear from the figure that the effectiveness of using isolation devices increase with increasing the height of the structure. If the response of frames isolated with LRB, having FPR of 3 under the KJM earthquake excitation is taken as an example it is found that the ratios of reduction in bending moments, relative to the fixed base frame, are $72 \%, 85 \%$ and $88 \%$ for 5, 10 and 20 story frames, respectively.

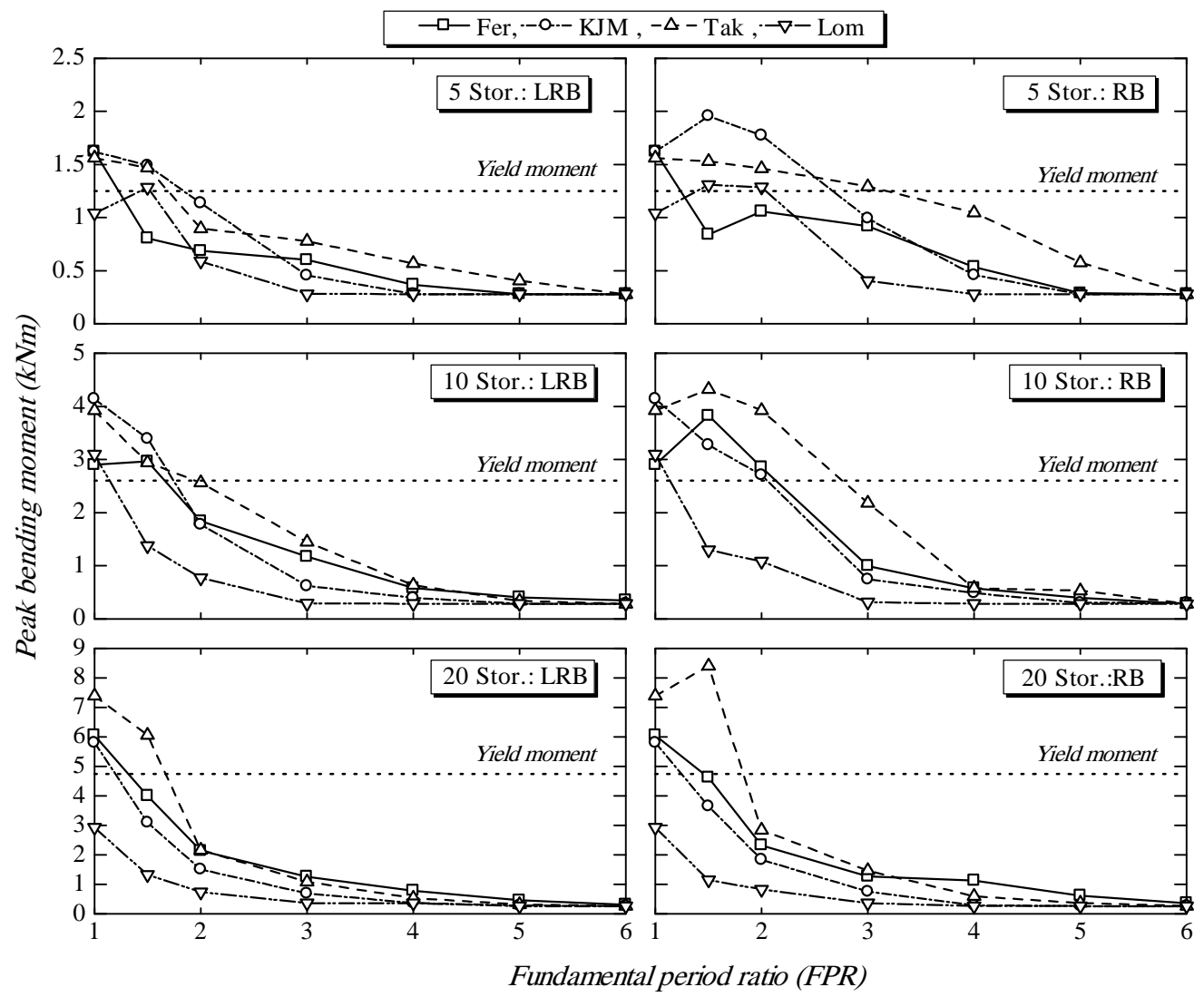

Fig. 7: Peak column bending moments. 
The benefits of seismic isolation become clear by examining the results of peak ductility demands which confirms the previous discussion about the response of column bending moments. The peak ductility demand gives a clear view about the performance of the structure as shown in Fig. 8. It is obvious that the fixed base frames require ductility demands increase with increasing the height of the building that the maximum peak ductility demands of fixed base frames are 6.0,9.20 and 13.40 for 5, 10 and 20 stories, respectively. It is observed that the ductility demand for frames isolated using LRB and having $F P R \geq 3.0$ did not increase 2.2. This value could be achieved with RB that can provide frames with $F P R \geq 4.0$

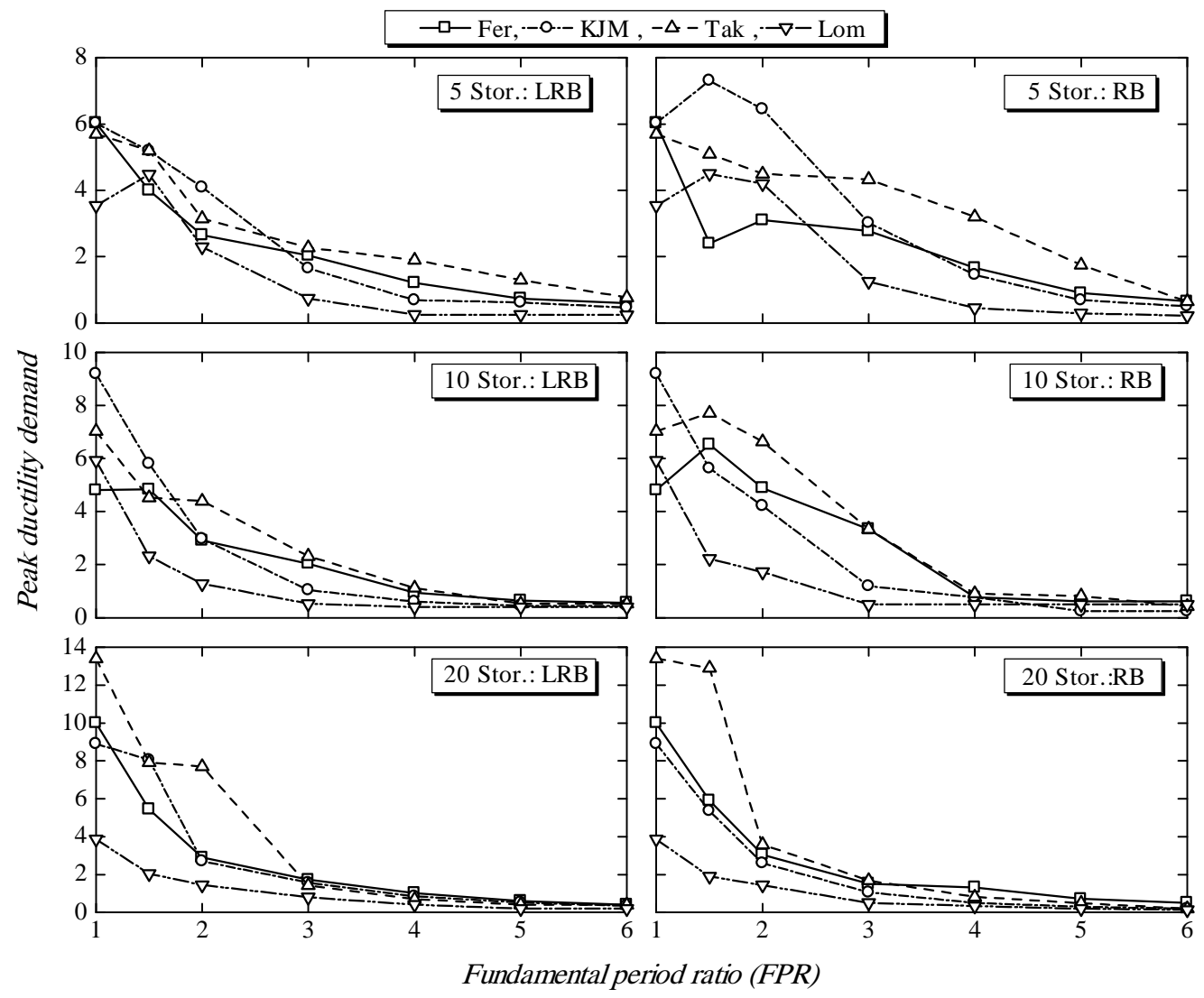

Fig. 8: Peak ductility demand.

One of the main responses that must be checked is the floor accelerations. The access in the accelerations, regardless to its bad effect on the structure elements, may cause damage to the equipments placed in the floors. It is clear that the fixed base frames suffer from very high values of accelerations up to $29 \mathrm{~m} / \mathrm{sec}^{2}$. The isolated frames have the ability of highly reducing the peak values of accelerations up to values of $F P R$ equal 3.0, for this value of $F P R$ the percentage reduction in acceleration could reach $75 \%$. For values of $F P R$ higher than 3, a slight enhancement in the performance could be observed. The response of peak floor accelerations is shown in Fig. 9. 


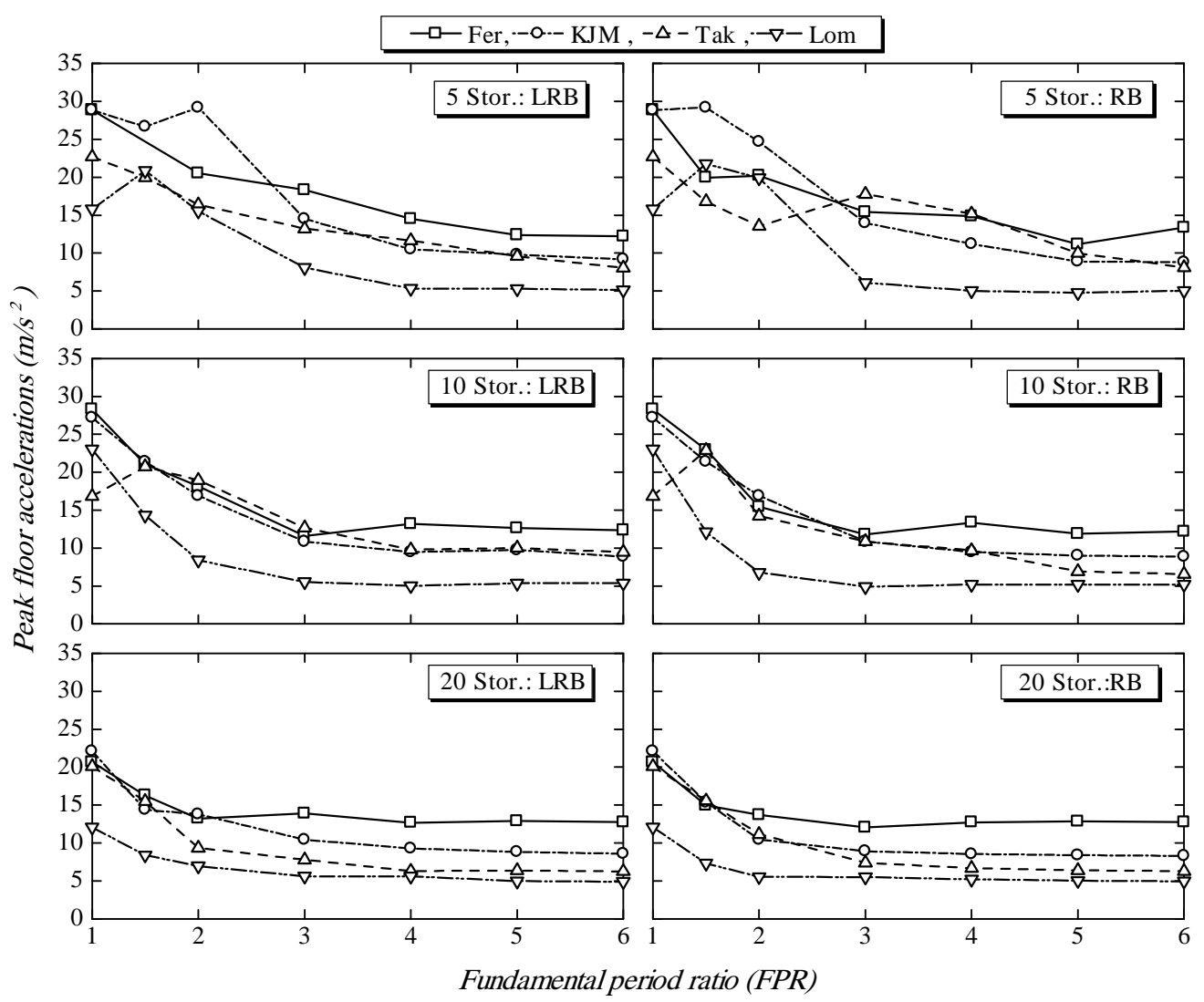

Fig. 9: Peak floor accelerations.

The structure displacement response is better represented by story drift ratios. As the trend of response to the different quakes is almost similar, the response of the frames with different heights under the Tak earthquake, the quake which in most cases requires the highest ductility demand is illustrated. The story drift ratios recorded at time of peak floor displacements are shown in Fig. 10. From the shown figure, it is obvious that the effectiveness of base isolation becomes clear when examining the response of story drift ratios for the presented cases. The fixed base frames have undergone high values of peak story drift ratio calculated as $1.25,1.39$ and 1.84 for the 5, 10 and 20 stories, respectively. The high increase in story drift ratios may cause damage to the sensitive equipments placed in the floors. Utilizing seismic isolation can highly reduce the harmful story drift to values less than $0.5 \%$ for 5 and 10 stories frame and less than $0.25 \%$ for the 20 stories frame as $F P R$ is $\geq 3.0$ for all studied cases except the 5 stories frame with $\mathrm{RB}$ which requires $F P R \geq 4.0$ to achieve the mentioned reduction value. It is also clear that the effectiveness of base isolation increases with increasing the number of stories. The decoupling of the structure from the ground motion by introducing a flexible interface between them can be better understood from Fig. 11 which represents the deflected shape of the 20 story frames with fixed base, isolated with RB and LRB providing FPR equal 3.0. 


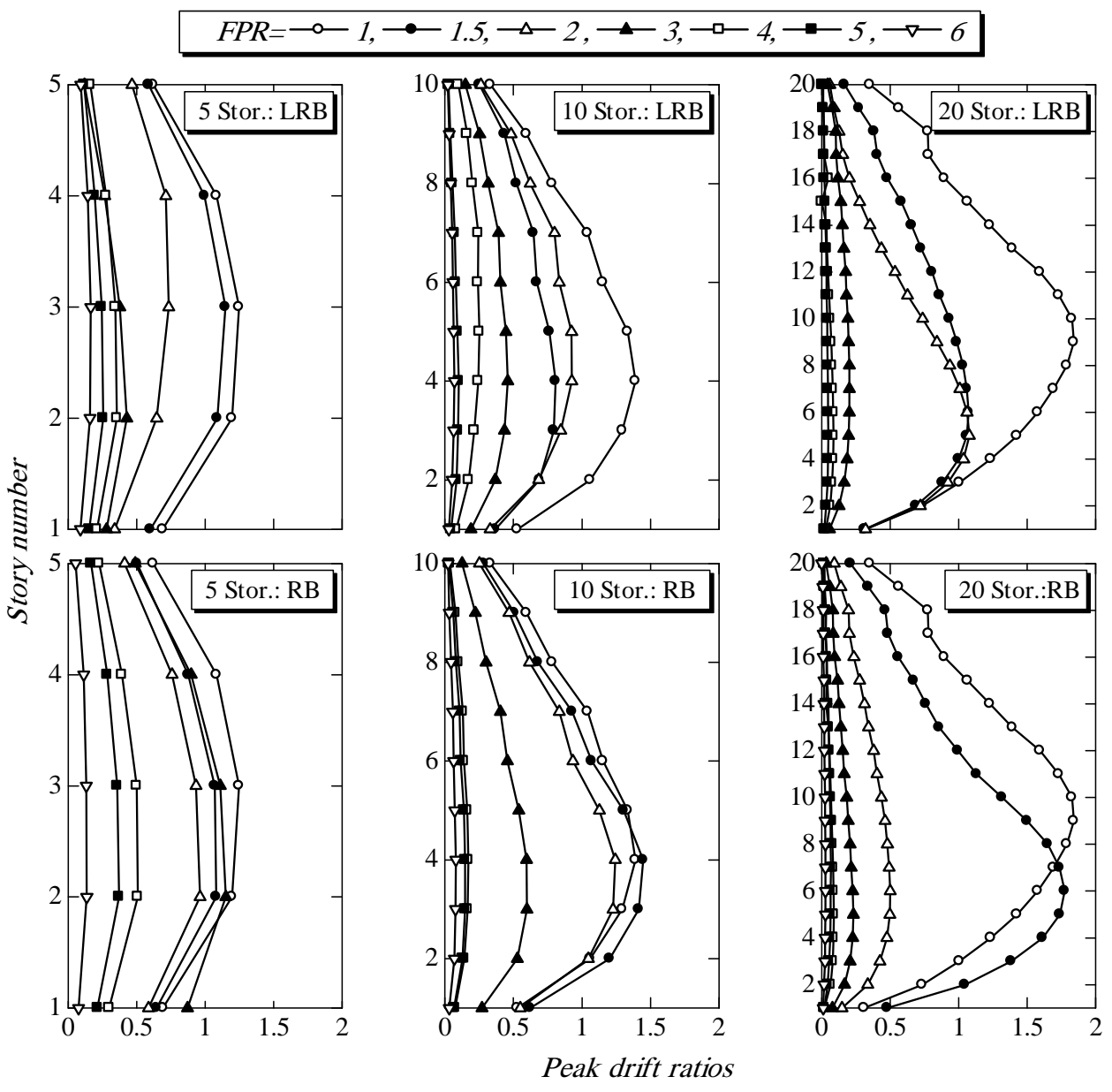

Fig. 10: peak story drift ratios due to Tak. Earthquake.
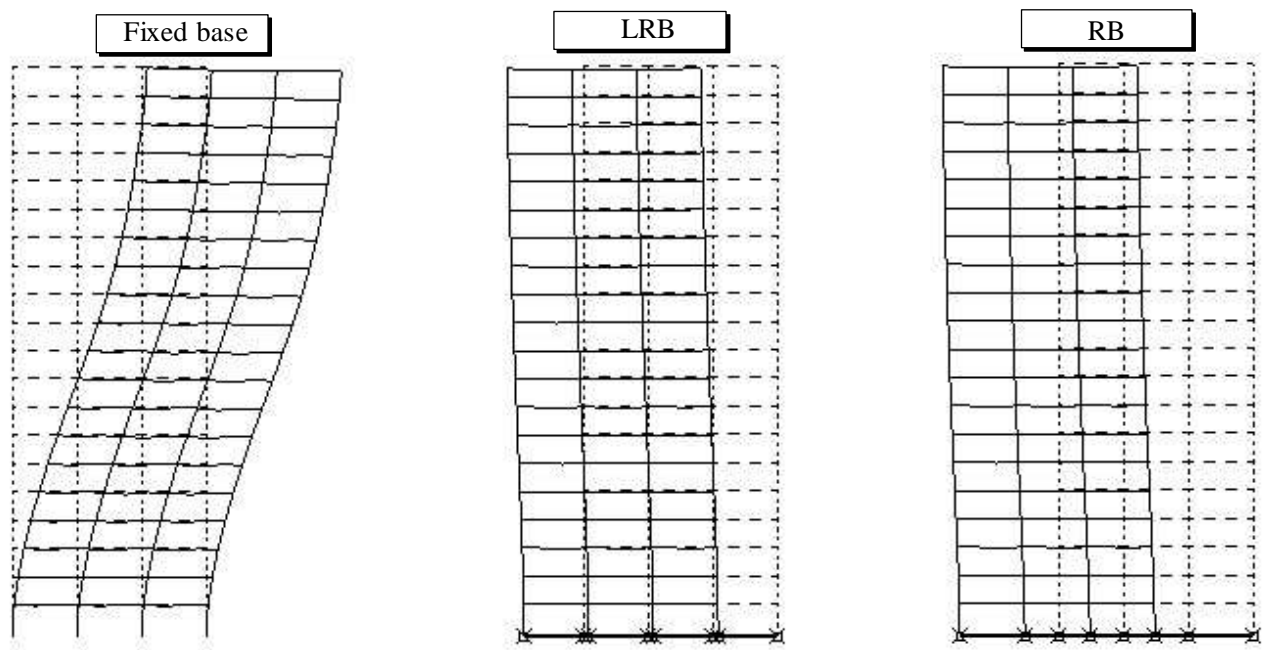

Fig. 11: Deflected shape of the selected frames (magnification factor $=20$ ). 
The Peak bearing displacement is with special concern in evaluating the response of isolated frames as it is of the main characteristic features required in the design of isolators. Figure 12 shows the peak response of isolator displacement when subjected to the different earthquake ground motions. The response of the bearings is generally, in most cases, increases up to FPR equal 3 or 4 after which there is a slight increase in the displacement of bearings. It is worth to mention that the lead core has a significant effect on controlling the bearing displacement. The peak bearing displacement of isolators under the different quake motions for frames isolated with LRB are $0.57 \mathrm{~m}$ for 5 story frame and $0.51 \mathrm{~m}$ for 10 and 20 story frames. These values for the same frames isolated with $\mathrm{RB}$ are $0.86 \mathrm{~m}$, and $0.88 \mathrm{~m}$. It is also clear from the shown figure that the effect of height of the applied excitation is much higher than the effect of height of the structure, which implies the importance of dynamic analysis for the isolated frames.

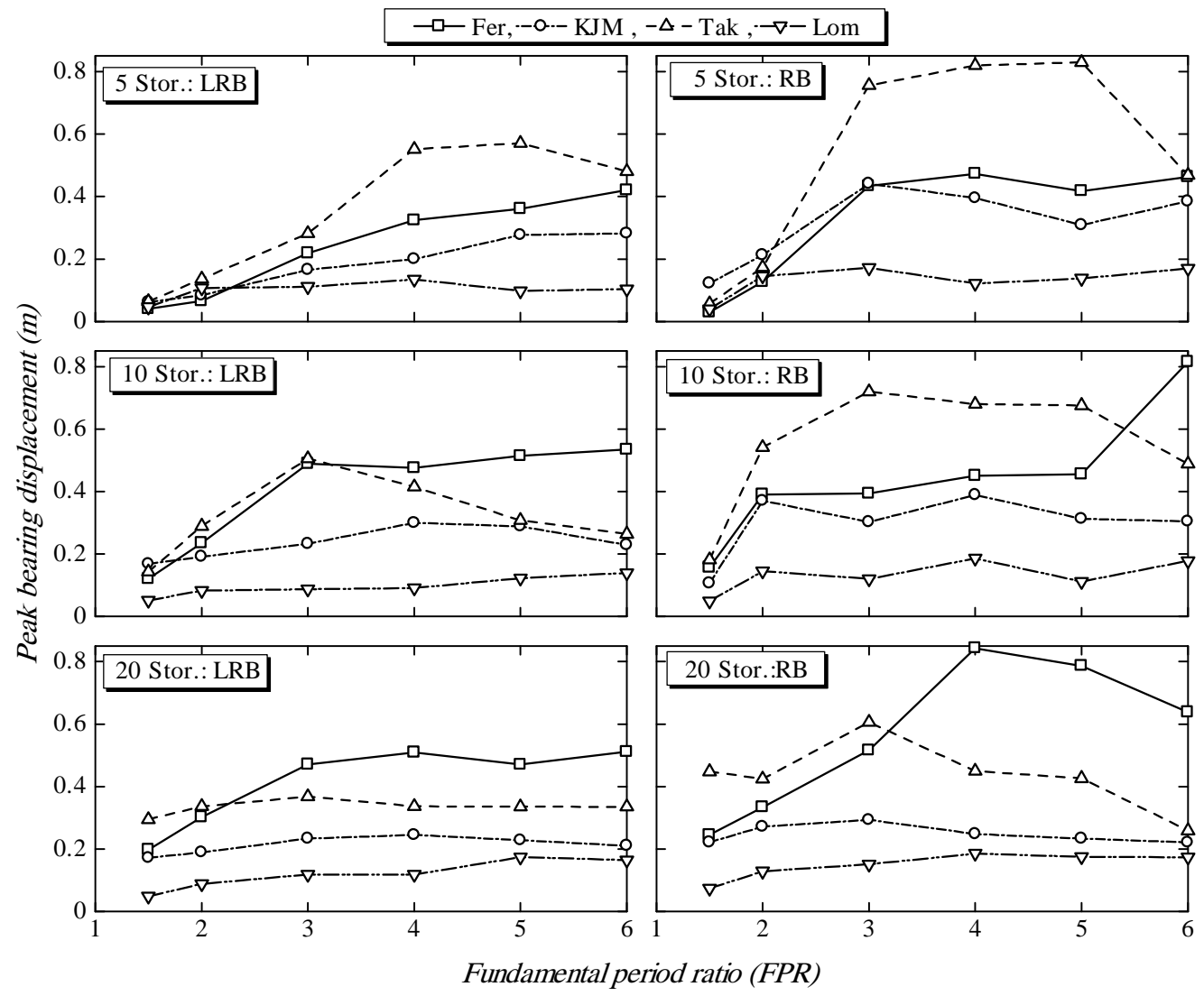

Fig. 12: Peak bearing displacement.

\section{CONCLUSIONS}

An analytical study is carried out to investigate the response of fixed base steel frame structures with different heights designed according to UBC 97 in comparison with the base isolated frames. Four different real accelograms are applied. Two types of elastomeric bearings are used as base isolators, the characteristic features 
of the isolators are represented by the fundamental period shift relative to fixed base frames, the following conclusions can be drawn out:

1) Although the fixed base test frames, with all different heights, are designed using the equivalent static load method to meet the requirements of the UBC 1997 for buildings exist in zone 4, they experienced high inelastic response under most of the applied quakes

2) The fixed base frames suffer from very high values of column bending moments, ductility demands, accelerations and story drift. Applying isolation bearings can sharply enhance these responses for $F P R$ equal 3.0 for LRB and $F P R$ equal 4.0 for RB. Beyond these ratios a rather slight enhancement in these responses can be observed, on the contrary, the bearing displacement usually increases.

3) This study reported, under all the applied excitation that as the height of building increases, the ductility demand increases and hence the need for base isolation increases.

4) The lead core inserted in the LRB has an announced effect in enhancing the behavior of frames isolated using LRB than those isolated using RB which require higher shift in period.

5) The main reason for the effectiveness of base isolation is the lengthening of the period of the structure to be shifted out of the dominant period of the earthquake.

6) The seismic forces transmitted to the base isolated frames with adequate flexibility is much less than the forces transmitted to the fixed base frames, hence the cost of base isolation systems could be balanced by the reduction in the cost of the superstructure.

\section{REFERENCES}

[1] Rai, D. C., Goel, S. C.: "Seismic evaluation and upgrading of chevron braced frames", J. Constructional Steel Research, Vol. 59, pp. 971-994, (2003).

[2] Japan Society of Civil Engineers: "Report on the Hanshin - Awaji earthquake disaster. Damage to civil engineering structures, bridge strucutures", Editorial Committee for the Report on Hanshin Awaji Earthquake disaster, December (1996).

[3] Elnashai, A. S.'Seismic Design of Steel Structures' Proceeding, Fourth Egyptian Training Course in Earthquake Engineering, Cairo (1990).

[4] Inudi, J. A., Kelly, J. M.: "Optimum damping in linear isolation systems", J. Earthquake Engineering and structural Dynamics, Vol. 22, pp. 583-598, (1993).

[5] Tsai, H. C., Hsueh, S. J.: "Mechanical properties of isolation bearings identified by a viscoelastic model" International J. Solids and Structures, Vol. 38, pp. 53-74, (2001).

[6] Jung, K. P., Lee, I. W.: " A comparative study on aseismic performance of base isolation systems for multi-span continuous bridge" Engineering Structures, Vol. 24, pp. 1001-1013, (2002).

[7] Mohamed, W. A., Hayashikawa, T, Aly, G. A. and Hussien, M. H.: "Study on seismic response of curved viaduct systems with different isolation conditions under great earthquake ground motion", Proceeding of Journal of Structural Engineering, JSCE, Vol. 49A, pp. 563- 572, (2002). 
[8] Tsai, H. G., Kelly, J. M.: " Seismic response of heavily damped base isolated systems" J. Earthquake Engineering and structural Dynamics, Vol. 22, pp. 633645, (1993).

[9] Costantinou, M. C., Soong, T. T., Dargush, G. F.: "Passive energy dissipation systems for structural design and retrofit", Multidisciplinary Center for Earthquake Engineering Research, (1998).

[10] Kelly, J. M.: " A seismic base isolation: review and bibliography, J. Soil Dynamics and Earthquake Engineering" Vol. 5, No. 3, pp. 202-216, (1986).

[11] Buckle, I. G., Mayes, R. L.: "Seismic isolation: History, application and performance - A world review" J. Earthqukae Spectra, Vol. 6, No. 2, (1990).

[12] Nagarajaiah, S., Xiaohong, S.: "Response of base- isolated USC hospital building in Northbridge earthquake", J. Structural Engineering, ASCE, Vol. 126, No. 10, pp. 1177- 1186, (2000).

[13] Fujita, T.: " Demonstration of effectiveness of seismic isolation in the HanshinAwaji earthquake and progress of applications of base isolated building. INCEDE, report 10, (1995).

[14] Chen, Q., Douglas, B. M., Maragakis, E. M., Buckle, I. G.: " Extraction of hysteretic properties of seismically isolated bridges from quick-release field tests", J. Earthquake Engineering and structural Dynamics, Vol. 31, pp. 333351, (2002).

[15] Park, J. G., Otsuka, H.: " Optimum yield level of bilinear seismic isolation devices", J. Earthquake Engineering and structural Dynamics, Vol. 28, pp. 941955, (1999).

[16] Molina, F. J., Werzeletti, G., Magonette, G., Buchet, P., Renda, V., Geradin, M., Parducci, A., Mezzi, M., Pacchiarotti, A., Federici, L., Masselloni, S.: Pseudodynamic tests on rubber base isolators with numerical substructuring of superstructure and strain - rate effect compensation" J. Earthquake Engineering and Structural Dynamics, Vol. 31, pp. 1563-1582, (1999).

[17] Paulson, T. J., Abrams, D. P., Mayes, R. L.: " Shaking - table study of base isolation for masonry buildings" J. Structural Engineering, ASCE, Vol. 117, No. 11, pp. 3315-3326, (1991).

[18] Martinelli, L., Mulas M. G., Perotti F. 'The Seismic Behavior of Steel MomentResisting Frames with Stiffening Braces", Engineering Structures, Vol. 20, No. 12, pp. 1045-1062, (1998).

[19] Vulcano, A.: " Comparative study of the earthquake and wind dynamic response of base - isolated buildings ", J. Wind Engineering and Industrial aerodynamics, Vol. 74-76, pp. 751-764, (1998).

[20] ICBO: "UBC-IBC Structural comparison and cross reference", (2000).

[21] Hwang, J. S., Chiou, J. M.: " An equivalent linear model of lead- rubber seismic isolation bearings, Engineering Structures, Vol. 18, No. 7, pp 528- 536, (1996).

[22] ADINA R\&D. ADINA User manuals - all volumes MA: ADINA R\&D. (1997).

[23] EGYPTIAN CODE OF PRACTICE FOR STEEL CONSTRUCTION AND BRIDGES (ECP), Code No. (205), 255 pp., (2001).

[24] Malangone, P., Ferraioli, M.: " A modal procedure for seismic analysis of nonlinear base-isolated multistory structures", J. Earthquake Engineering and structural Dynamics, Vol. 27, pp. 397-412, (1999). 


\section{تقييم السلوك الزلزالي للمنشآت الإطارية و المزودة بأنظمة للعزل وذات ارتفاعات مختلفة الإطاتة}

أدي الانهيار الجزئي أو الكلي الذي حدث لهجموعة كبيرة من الإطـار ات المعدنيـة

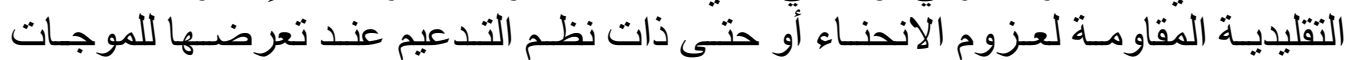

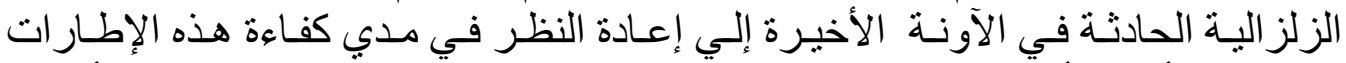

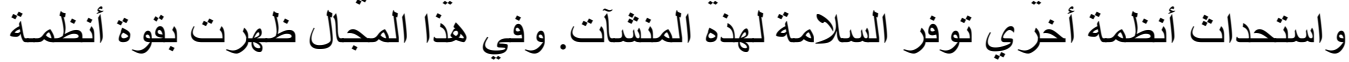
العزل الزلز الي (base isolation systems) و التي بـأ ينتثـر استخدامها في الأعوام

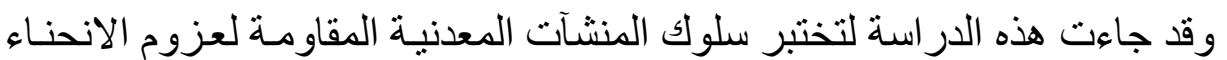

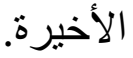

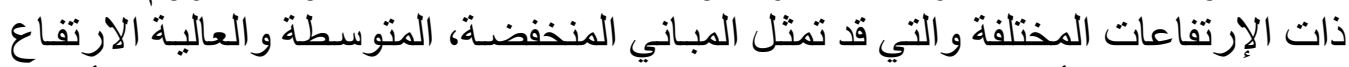

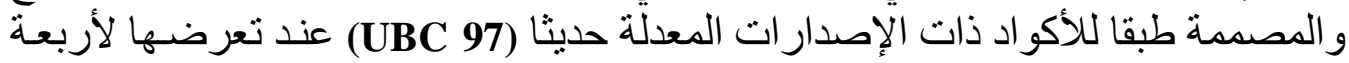

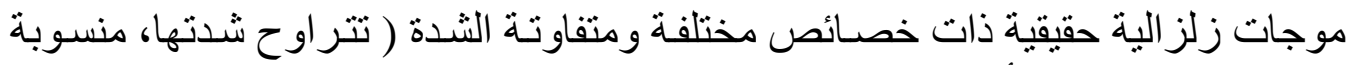

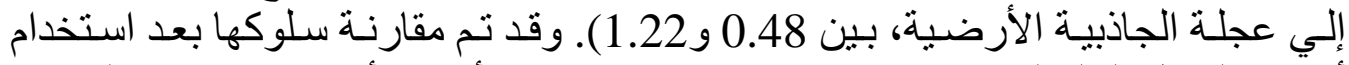

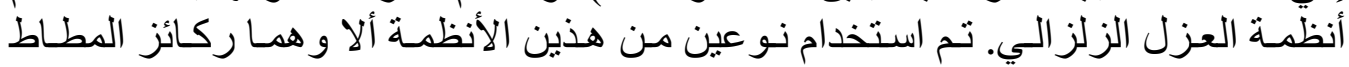

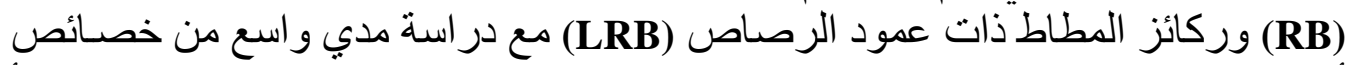

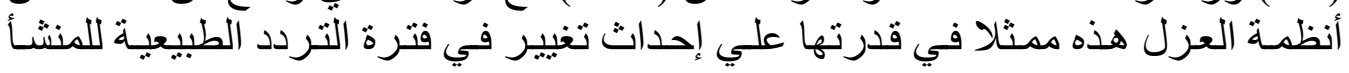

التقليدي (fundamental period ratio)

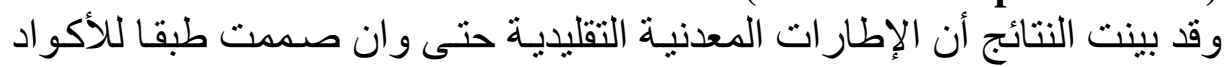

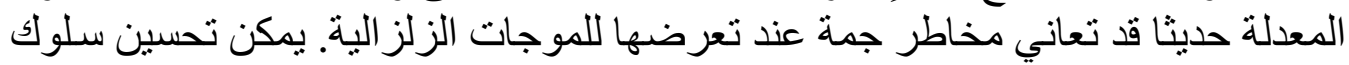

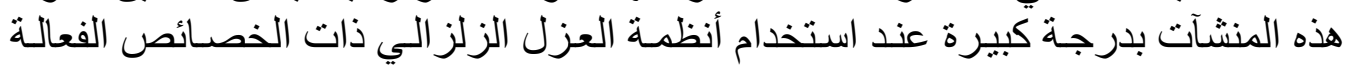

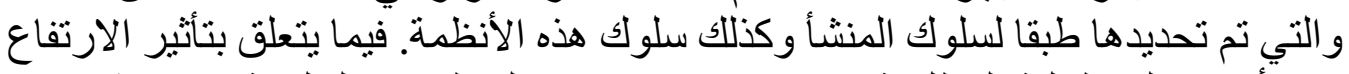

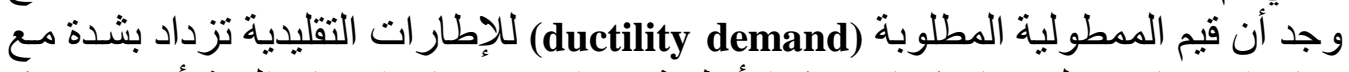

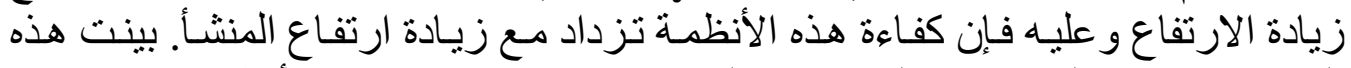

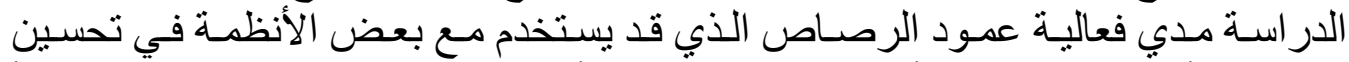

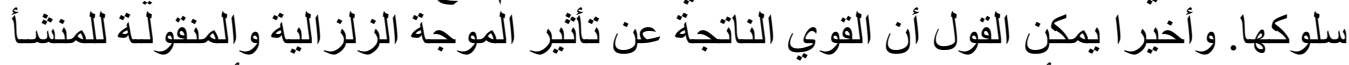

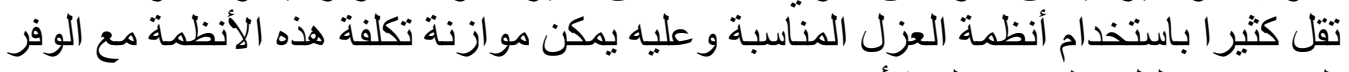
الناتج من تقليل قطاعات المنشأ. 